\title{
Howard walnut trees can be brought into bearing without annual pruning
}

by Bruce D. Lampinen, John P. Edstrom, Samuel G. Metcalf, William L. Stewart, Claudia M. Negron and M. Loreto Contador

In traditionally managed Howard walnut orchards, trees are pruned annually during the orchard development phase, an expensive operation in terms of labor and prunings disposal costs. Our observations and some prior research by others had suggested that pruning may not be necessary in walnut. In a trial of pruned and unpruned hedgerow trees over 8 years, beginning a year after planting, we documented canopy growth, tree height, yield and nut quality characteristics and also the effects of fruit removal. Pruning altered canopy shape but did not lead to increases in canopy development, yield or nut quality. Although fruit removal stimulated more vegetative growth in both the pruned and unpruned treatments, fruit removal did not result in an increase in midday canopy photosynthetically active radiation interception or cumulative yield when fruit removal was stopped after year 4. After 8 years, there were no significant differences in tree height, nut quality or cumulative yield among any of the treatments, which suggests that not pruning young Howard orchards could provide a net benefit to growers.

$\mathrm{T}$ he recommended training to develop the tree structure of lateralbearing walnut (Juglans regia L.) varieties such as Howard during the first 4 years after planting is to use a combination of heading and thinning cuts (Aldrich 1972; Hasey et al. 1998). After year 4 , heading of scaffolds is continued until the tree has reached the desired size, which usually occurs by year 6 to 8 . The costs associated with such pruning and disposal of prunings are high - around $\$ 1,134$ per acre total for years 1 to 6 (UCCE 2012). Some research has indicated that no significant difference in yield results from pruning walnuts (Olson et al. 1990), but that trial was conducted on mature trees. Our observations on breeding program orchards at UC Davis and grower orchards in California have suggested that walnut trees can grow and produce well without pruning even in the early years, so we initiated a trial to gather data over 8 years in a developing Howard walnut orchard.

Online: http://californiaagriculture.ucanr.edu/ landingpage.cfm?article=ca.E.v069n02p123\&fulltext=yes doi: 10.3733/ca.E.v069n02p123
In traditional pruning, after the first dormant pruning, relatively few shoots

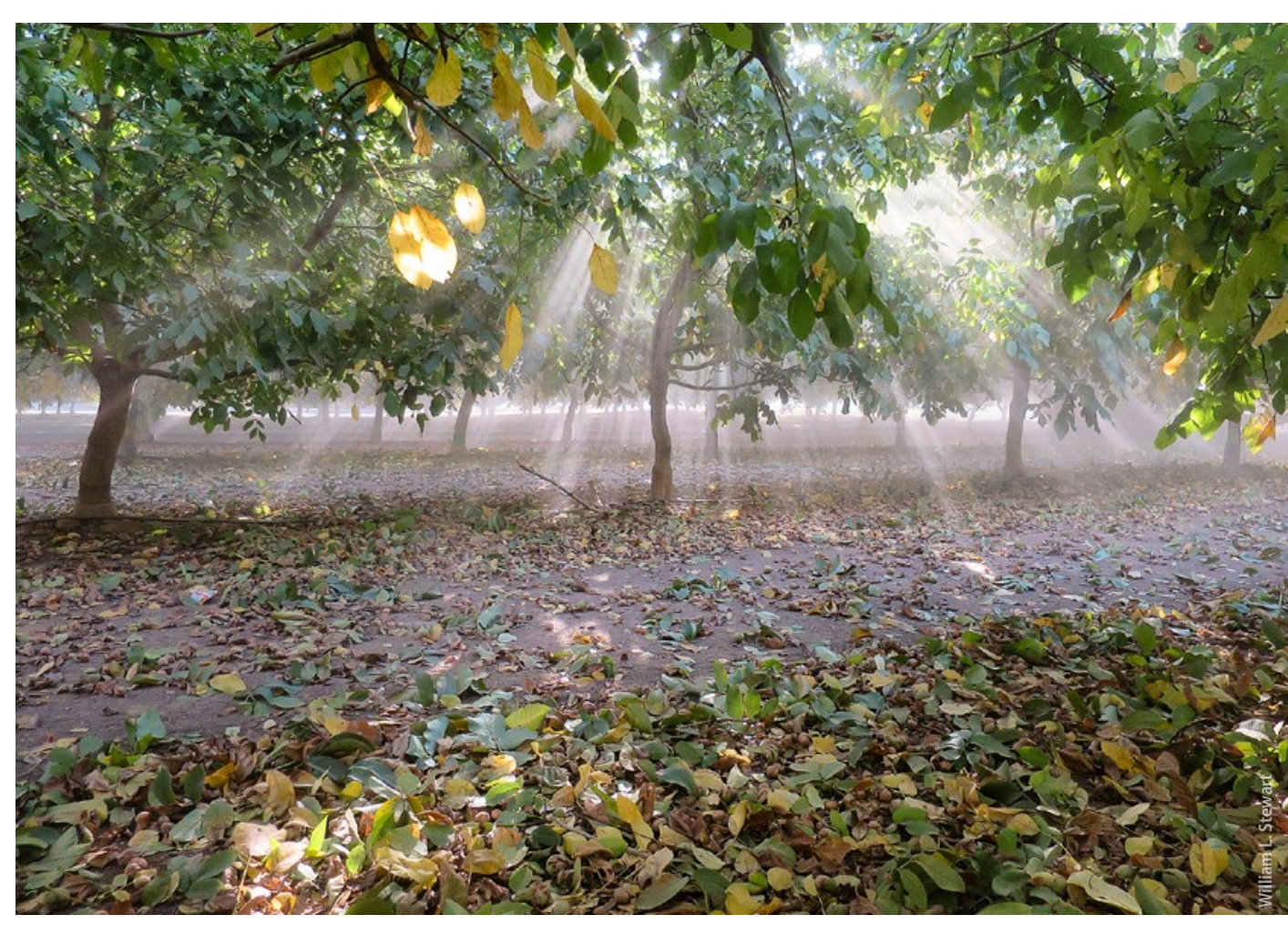

Data was gathered over 8 years in a developing Howard orchard to see if trees can grow and produce well without pruning. below the terminal bud usually break dormancy and grow, but those that do, grow more vigorously than shoots in unpruned trees. With repeated heading cuts over time, pruned trees develop a dense canopy, which can lead to shading-related dieback of interior limbs by year 5 or 6 . In contrast, branches of unpruned trees elongate and produce side shoots, which fill the space around the main branches. The elongation growth on individual branches tends to occur every other year. The result is a more open canopy structure since fewer branching points are generated.

The size of a fruit or nut tree canopy affects the amount of light intercepted, which affects yield. A curvilinear relationship has been documented between intercepted PAR (photosynthetically active radiation) and canopy dry matter accumulation in apple (Wunsche et al. 1996), peach (Grossman and DeJong 
1998) and macadamia (McFadyen et al. 2004). A model of potential crop yields by Adam et al. (2011) suggests that the use of light interception is a better estimation of yield sensitivity than an approach that incorporates biomass production. A positive correlation between total canopy light interception and yield has been reported in apple (Barritt et al. 1991; Jackson 1980; Wunsche and Lakso 2000), with an estimated optimal balance between interception, productivity and fruit quality at approximately $70 \%$ to $80 \%$ interception (Rom 1991).

The objective of our study was to assess the impacts of traditional pruning and no pruning on tree growth and productivity. Fruit removal treatments were incorporated into the trial to assess the impact of crop load on vegetative growth, to see whether trees "stall out" if they are not pruned. The common wisdom is that early cropping can lead to competition with vegetative growth, making final tree size smaller, and that pruning prevents this from happening.

\section{Colusa County orchard}

The study began in the spring of 2004 following the second growing season in a Howard walnut orchard planted in 2002 on Paradox seedling hybrid rootstock in Colusa County, California. The soil profile was a mixture of the Arbuckle-Hillgate complex, Hillgate loam and Arbuckle sandy loam series (California Soil Resource Lab 2008).

Trees were planted at a spacing of 12 by 25 feet ( 3.75 by 7.8 meters), with a northsouth row orientation.

From 2002 to 2004, irrigation was by single line drip; in 2005 the orchard was converted to microsprinkler irrigation. Irrigation was scheduled using the water budget method, with the goal of supplying orchard evapotranspiration needs with adjustments based on soil moisture monitoring data.

Early training. All trees had received some hedgerow training already. Heading cuts had been made at about 4 to 5 feet (1.25 to 1.5 meters) during the dormant season following the first growing season, and scaffolds had been selected in the dormant season following the second growing season. At the start of the trial, spring 2004, heading cuts were made on the trees in the pruned treatments; the selected scaffolds were left unheaded in the unpruned treatments.

Pruning and fruit removal. Differential pruning and defruiting treatments were initiated in the spring of 2004. Five replications of each of four pruning and

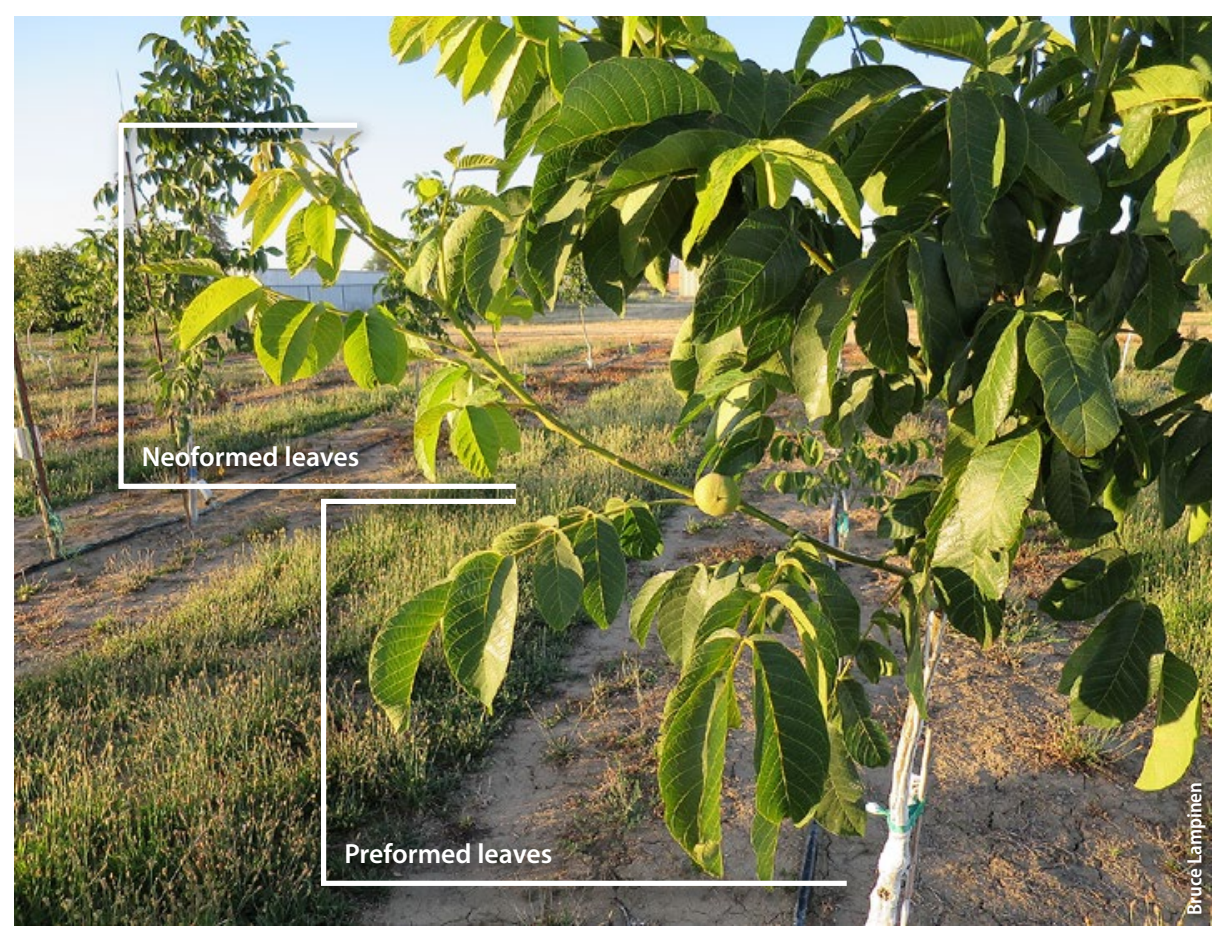

Canopy growth in young walnut trees is bimodal: Preformed growth forms in the bud during the previous season, and neoformed growth forms during the current season.

defruiting treatments were implemented in a randomized block design: (T1) unpruned with no fruit removed, (T2) unpruned with fruit removed, (T3) pruned with no fruit removed and (T4) pruned with fruit removed. Each replication consisted of three rows with four trees per row. The two trees in the middle of the center row of each 12-tree replication were used for detailed treatment monitoring, but treatments were applied to all 12 trees.

The pruning treatment (in T3 and T4) consisted of removing approximately onethird of the previous year's growth on all shoots that elongated the previous season, thinning shoots that were too close together and removing in-season branching points (sylleptic shoots). No cuts were made on unpruned treatment trees except to remove limbs that were either in the way of tractor traffic through the orchard or impeded the view of the trunk for the mechanical shaker operator. The weight of the removed branches was included in the fresh pruning weights reported by treatment. The pruning treatment was terminated in 2007.

In the spring of 2004, 2005 and 2006, all fruit were removed by hand-thinning from treatments T2 and T4 in mid-April, when fruit were approximately 0.24 inch ( 0.6 centimeter) in diameter, to assess the impact of crop load on vegetative growth. Fruit were not removed from these treatments after 2006.

\section{Data collection, 2003 to 2010}

Midday stem water potential (MSWP) was measured approximately every other week on 10 trees per treatment from 2005 through 2010. Leaves were bagged at least 15 minutes before measurements were taken with a plant pressure chamber (Soil Moisture Equipment, Goleta, CA) between 1 p.m. and 3 p.m. following methods described by Fulton et al. (2001).

Canopy growth. On young walnut trees, shoot growth is bimodal. The portion of the shoot that is formed during the previous season and overwinters in the dormant bud is known as the preformed portion of the shoot; the portion of the shoot that forms during the current growing season is known as the neoformed portion of the shoot (Sabatier and Barthélémy 2001). Preformed shoot growth is completed by early May, and shoot growth from June through fall is neoformed. The number of shoots 

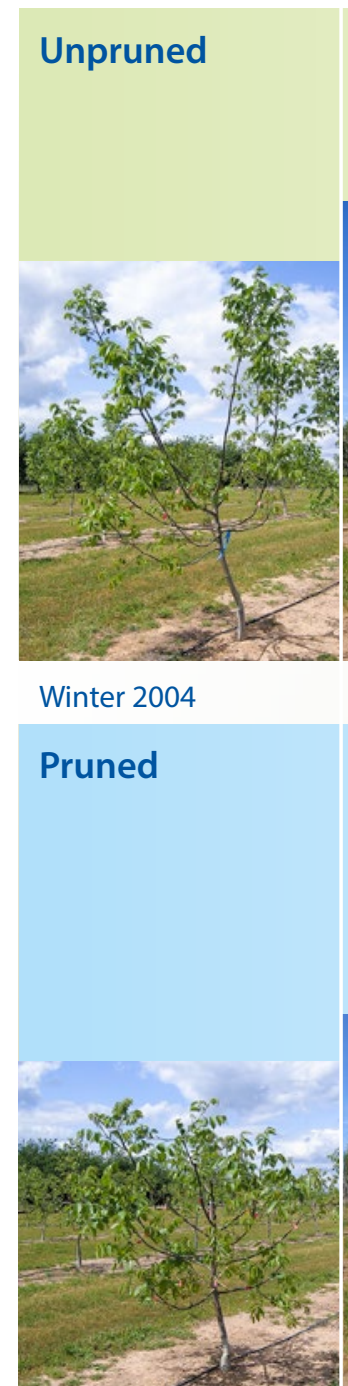

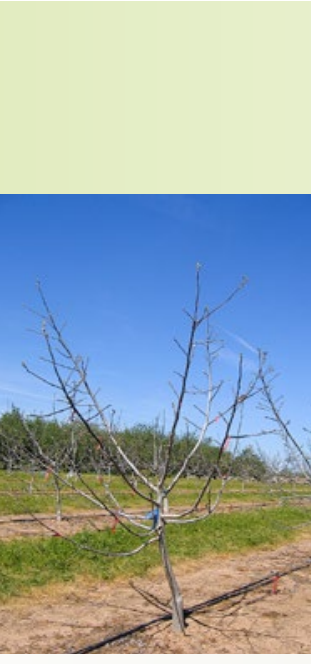

2005

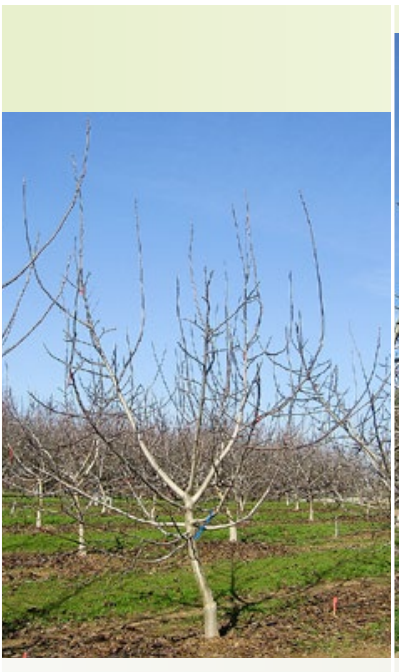

2006

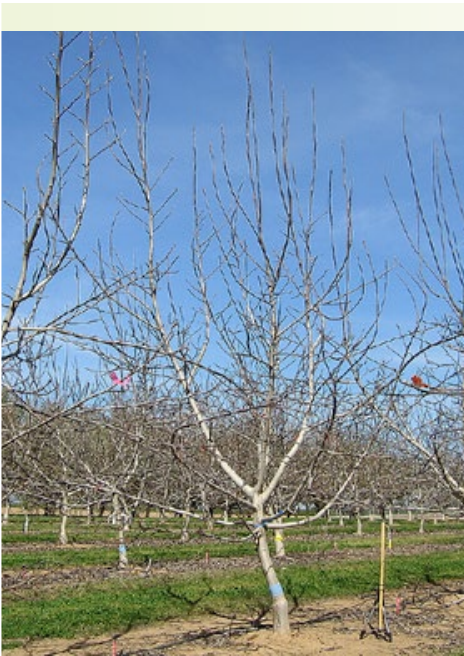

2007

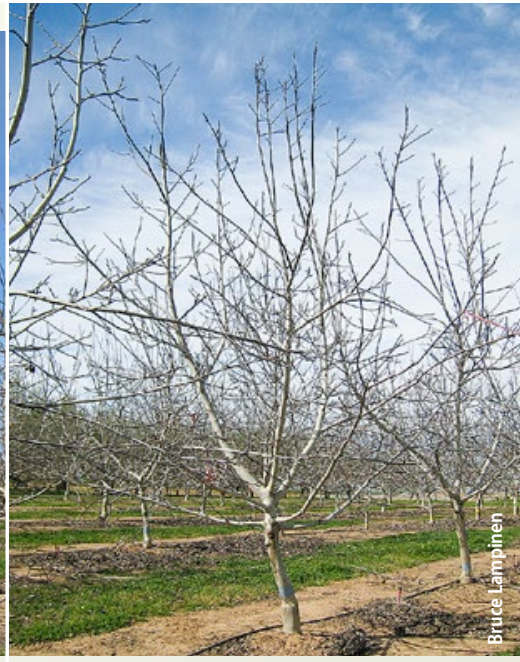

2008
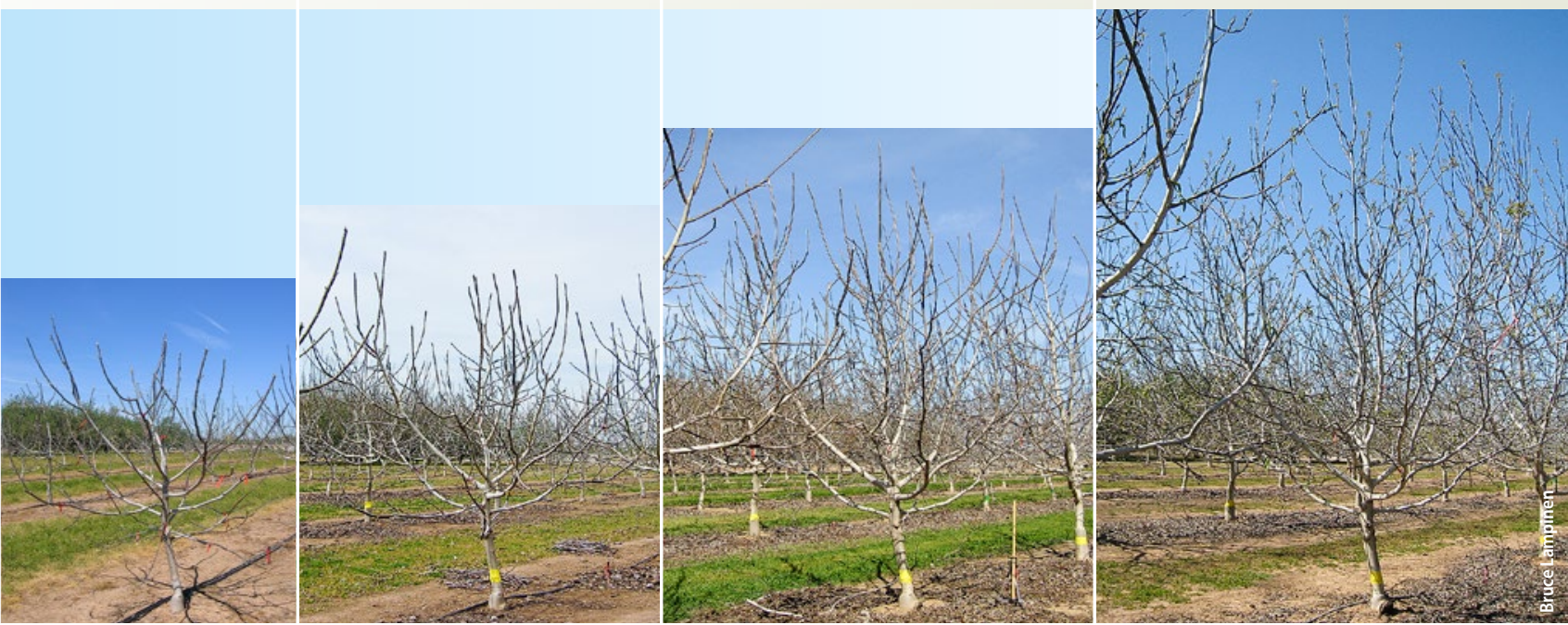

Comparison of yearly tree development in unpruned and pruned Howard walnut trees.

producing neoformed growth was counted on each tree on two dates during summer in 2005 to 2007 and one date in 2008. Terminal shoot growth was measured at the end of the growing season in 2004, 2005, 2006 and 2007. Tree height and trunk circumference were measured at the end of each growing season from 2003 through 2010.

Midday canopy PAR interception was measured in late June to early July from 2005 to 2008 using a Sunfleck Ceptometer (Decagon Devices, Pullman, WA). A grid of 100 measurements was taken in each replication around the same 10 trees per treatment used for MSWP monitoring, using methods described by Grossman and DeJong (1998). In 2009 and 2010, midday canopy light interception was mapped in the same area as the grid using a mobile platform light bar (Lampinen et al. 2012).
Nut quality and harvest. The number of sunburned nuts on each tree were counted in early September in 2004 to 2008. The percentage of sunburned nuts was then calculated using the estimated total number of nuts on the tree. In 2004, and weighed in the field. In 2009 and 2010, nuts were mechanically shaken, picked up with a commercial harvester and weighed in the field using load cellequipped harvest trailers. In all years, subsamples were taken for hulling and

\section{There was more shading-related lower canopy dieback in the pruned treatments than in the unpruned treatments.}

yield was estimated by counting nuts on the trees and multiplying by average dry weight of nuts. In 2005 and 2006, trees were harvested by hand-shaking, and all nuts were collected, hulled, dried, counted and weighed. Nuts were removed by mechanical shaking in 2007 and 2008. The nuts were run through a small hand-pulled huller-blower with a rotating drum to remove hulls and leaves drying to allow conversion to dry in-shell weight. Samples were analyzed for quality each year from 2005 to 2010. Statistical analysis $(P \leq 0.05$, Duncan's means test) was conducted using SAS Software (SAS Institute, Cary, NC).

\section{Affects on growth, yield, nut quality}

Pruning and fruit removal treatments had only small impacts on MSWP. In 2005, 
2006 and 2009, there were no significant treatment differences in seasonal average MSWP (table 1). In 2007, 2008 and 2010, T1 and $\mathrm{T} 4$ tended to be slightly more stressed than T2 and T3, but the differences were small (approximately 0.05 MPa) and unlikely to have had significant impacts on tree growth, yield or quality.

Canopy growth. Pruning stimulated more neoformed shoot growth in 2005, 2006 and 2007 (fig. 1). In 2005 and 2006, there were fewer shoots growing in the pruned treatment in late summer than in the unpruned treatment trees (fig. 1). The unpruned trees tended to have a more open canopy structure, while the pruned trees tended to be more dense. The differences were less pronounced by 2010. However, there was more shading-related lower canopy dieback in the pruned treatments than in the unpruned treatments. Fruit removal exacerbated these differences, with the worst shading-related

TABLE 1. Seasonal average midday stem water potential (MPa)* by treatment, 2005-2010

\begin{tabular}{lcccccc}
\hline \hline Treatment & $\mathbf{2 0 0 5}$ & $\mathbf{2 0 0 6}$ & $\mathbf{2 0 0 7}$ & $\mathbf{2 0 0 8}$ & $\mathbf{2 0 0 9}$ & $\mathbf{2 0 1 0}$ \\
\hline T1. Unpruned & $-0.608 \mathrm{a} \dagger$ & $-0.625 \mathrm{a}$ & $-0.664 \mathrm{ab}$ & $-0.490 \mathrm{~b}$ & $-0.625 \mathrm{a}$ & $-0.509 \mathrm{ab}$ \\
T2. Unpruned, fruit removed & $-0.609 \mathrm{a}$ & $-0.596 \mathrm{a}$ & $-0.645 \mathrm{a}$ & $-0.423 \mathrm{a}$ & $-0.573 \mathrm{a}$ & $-0.467 \mathrm{a}$ \\
T3. Pruned & $-0.664 \mathrm{a}$ & $-0.643 \mathrm{a}$ & $-0.643 \mathrm{a}$ & $-0.455 \mathrm{ab}$ & $-0.580 \mathrm{a}$ & $-0.472 \mathrm{a}$ \\
T4. Pruned, fruit removed & $-0.664 \mathrm{a}$ & $-0.629 \mathrm{a}$ & $-0.733 \mathrm{~b}$ & $-0.503 \mathrm{~b}$ & $-0.642 \mathrm{a}$ & $-0.553 \mathrm{~b}$ \\
\hline
\end{tabular}

* Measured on 10 trees for each replication approximately every 2 weeks during the growing season.

† Letters indicate statistical significance $(P \leq 0.05$ Duncan's means test) among treatments within a year.

lower canopy dieback occurring in the pruned treatment with fruit removed (T4).

Fruit removal had little effect on overall vegetative growth in the first and second year of the trial, when numbers of fruit per tree were few, but by the third year, shoot growth tended to be more extensive on trees with fruit removed, both in terms of the number and length of shoots; however, this did not result in a significant increase in tree height (fig. 2), midday canopy light interception (fig. 3) or cumulative yield (fig. 4) by 2010.
In 2005, 2006 and 2007, fruit removal tended to result in more fresh pruning weight removed, but the effect was significant for only the pruned treatments (fig. 5). Only a small amount of dormant pruning was applied in 2008. In early June of 2008, the crop load was weighing down branches, making the drive row impassable, and summer pruning was conducted on all treatments to allow passage through the orchard. The problem was most severe in T3 and T4, the pruned treatments, possibly due to heavier
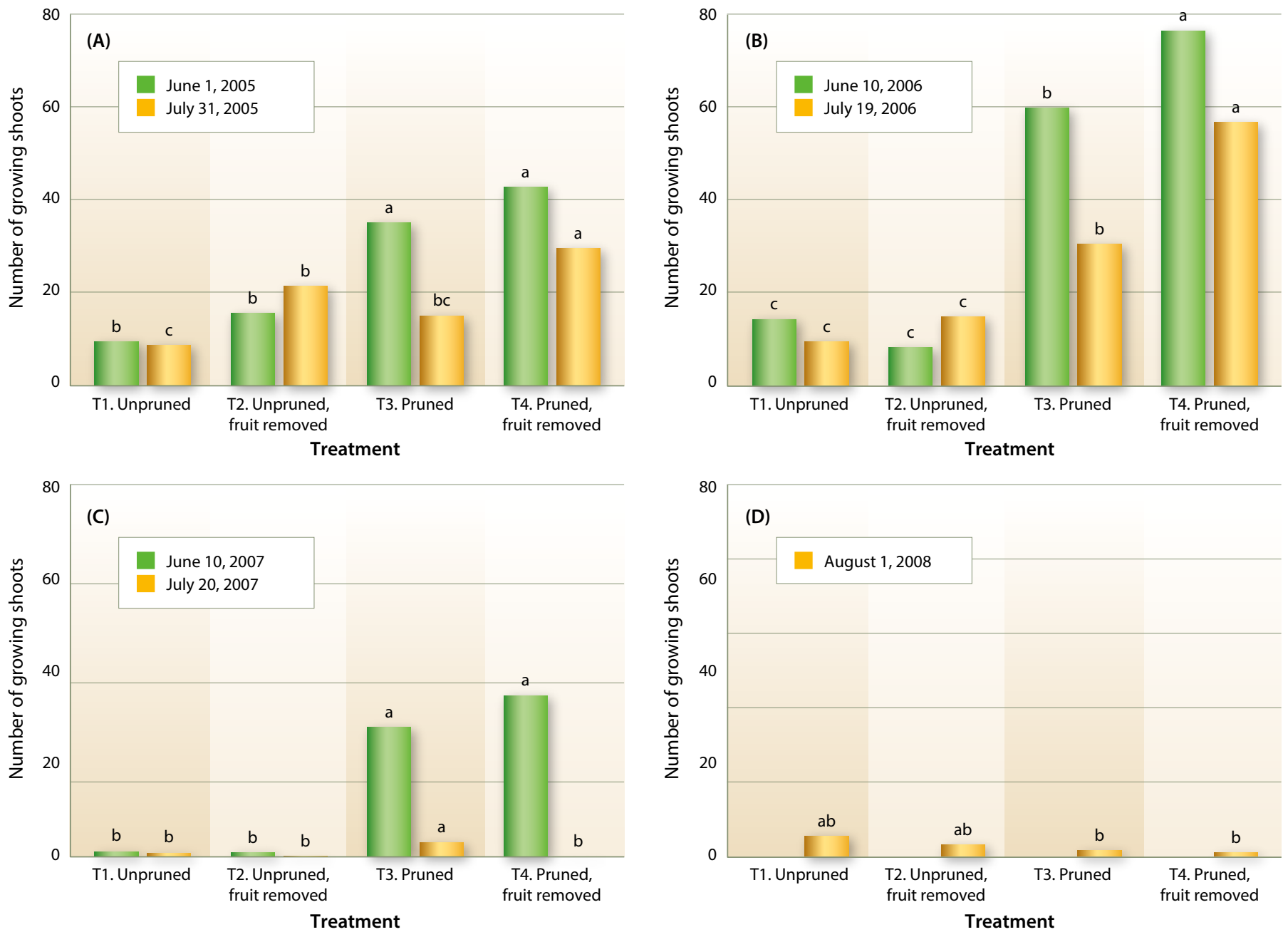

Fig. 1. Average number of neoformed shoots growing per tree on (A) June 1 and July 31, 2005, (B) June 10 and July 19, 2006, (C) June 10 and July 20, 2007, and (D) Aug. 1, 2008, by treatment. Letters indicate a significant difference $(P \leq 0.05)$ among treatments on a specific date using Duncan's means test. 
cropping as a result of the termination of pruning for the first time the previous winter. The pruning weights in figure 5 do not include the weights from the summer pruning. Severity of summer pruning ranked from most to least severe was $\mathrm{T} 4$ $>\mathrm{T} 3>\mathrm{T} 2>\mathrm{T} 1$, with approximately twice as much wood removed from $\mathrm{T} 4$ than from T1.

There were no significant differences in trunk cross-sectional area between treatments in any year (data not shown).

Midday canopy PAR interception (reported as a percentage of total available PAR) increased from about 30\% in 2005 to $70 \%$ by 2010 . There were no significant differences in June/July midday canopy PAR interception among treatments in any year (fig. 3). Since midday canopy PAR interception sets an upper limit to potential productivity and no differences were found among treatments, we would not expect major yield differences among treatments once fruit removal ceased; and no significant differences in yield were observed in 2008, 2009 and 2010, after the fruit removal treatment was terminated (fig. 6).

Yield and quality. In 2005, the unpruned treatments had significantly higher yields than the pruned treatments (fig. 6). However, after 2005 these early differences did not persist (fig. 6). In 2007, T2, unpruned and fruit removed in 2003 through 2006 but not in 2007, had a significantly higher yield than any other treatment; T4, pruned and fruit removed, did not have a significantly high yield (fig. 6). In 2008, 2009 and 2010, there were no significant treatment differences in yield (fig. 6).

There were no differences in cumulative yield between T1 (unpruned, no fruit removed) and T3 (pruned, no fruit removed) in any year (fig. 4). Cumulative

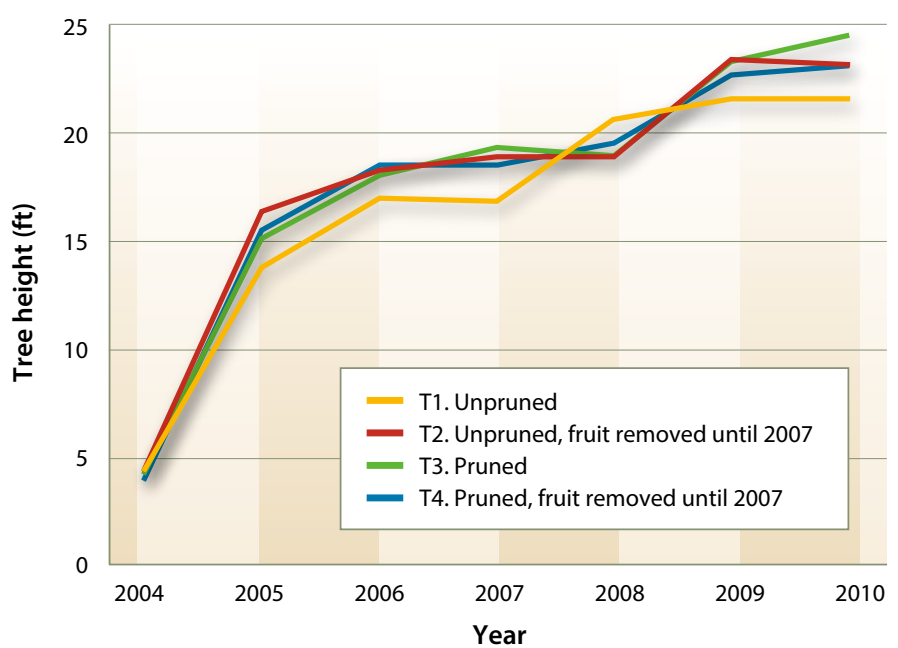

Fig. 2. Tree height, in feet, measured at the end of each growing season. There were no significant treatment differences in height on any date. ( 1 foot $=0.3048$ meter.)

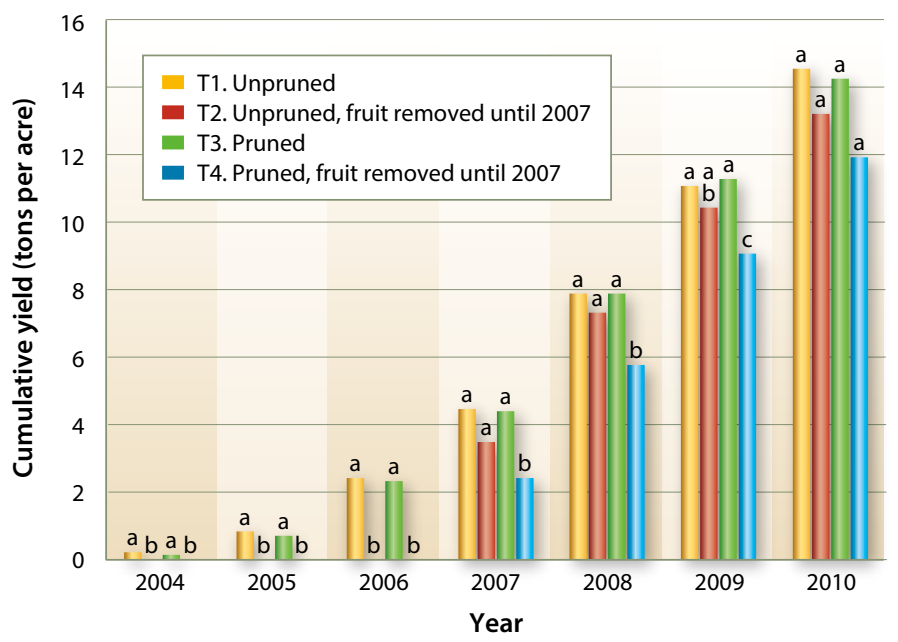

Fig. 4. Cumulative yield (tons per acre) by year and treatment. Letters indicate a significant difference $(P \leq 0.05)$ among treatments within a given year using Duncan's means test. ( 1 ton per acre $=2,241.7$ kilogram per hectare.)

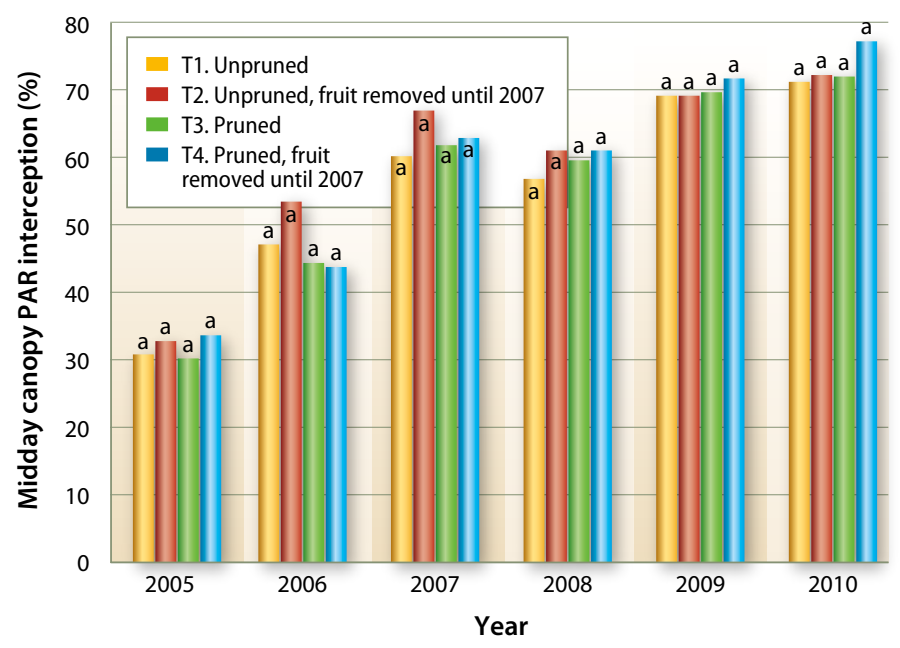

Fig. 3. Midday canopy PAR interception measured on June 22, 2005, June 15,2006 , June 18, 2007, July 3, 2008, June 23, 2009 and July 9, 2010. Letters indicate a significant difference $(P \leq 0.05)$ among treatments within a given year using Duncan's means test.

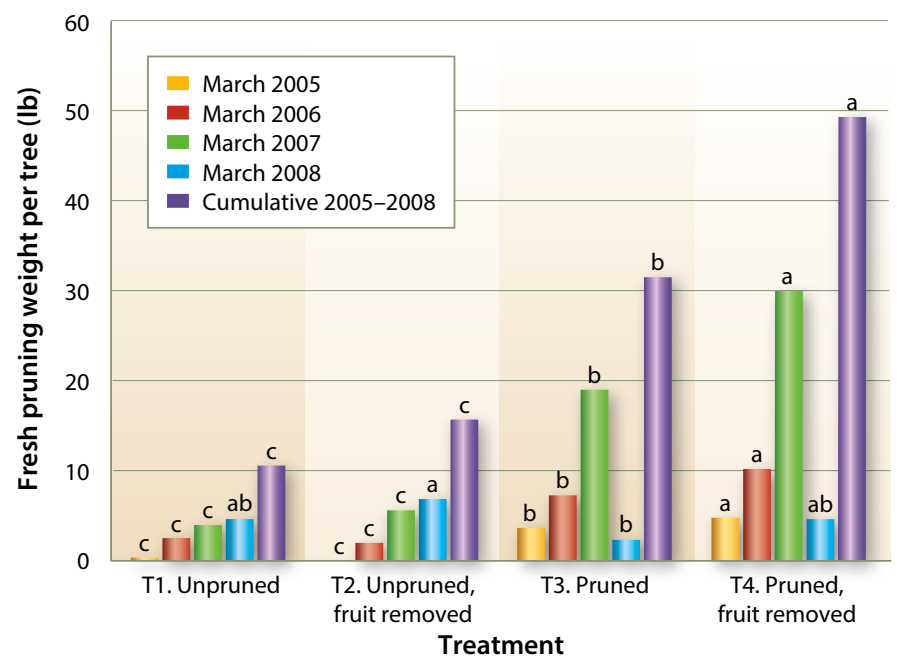

Fig. 5. Fresh pruning weight per tree, in pounds, measured on day of pruning. Pruning weight from unpruned trees is of limbs removed because of wind breakage or because they impeded orchard operations. Letters indicate significant difference among treatments within a given year (or for cumulative total) at $P \leq 0.05$ with Duncan's means test. ( 2.20 pounds $=$ 1 kilogram.) 


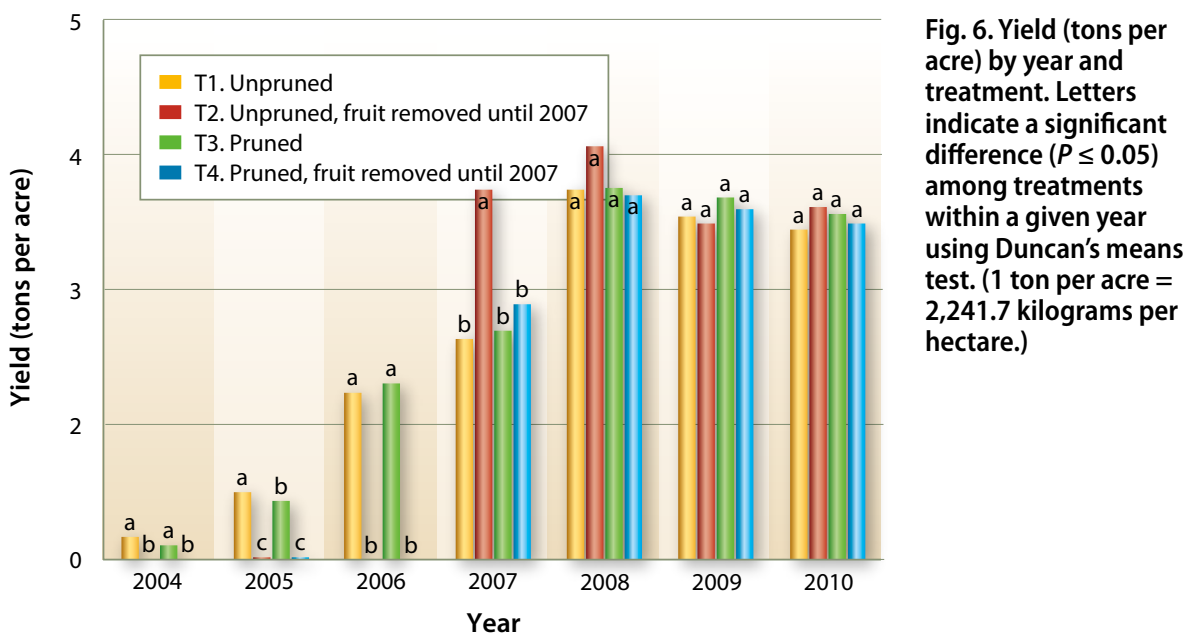

yield for T2 was not significantly lower than T1 and T3 in any year after fruit removal ceased in 2007, while T4 cumulative yields were similar to T1 and T3 by 2010 (fig. 4).

Quality of nuts from this trial was generally good, both in terms of nut size and color. There were no significant treatment impacts on any quality attributes in any year except in 2008, when the nuts in T1 were slightly larger (with similar crop load) than the nuts in T3 (data not shown). There were no significant treatment impacts on sunburn in any year measured (data not shown). Sunburn was not measured in 2009 or 2010 due to the difficulty of getting an adequate assessment with the large tree size.

\section{No benefits to pruning}

After 8 years of pruned and unpruned treatment imposition, there were minor differences in MSWP (table 1) but no significant differences in tree height (fig. 2), nut quality (data not shown) or cumulative yield (fig. 4) among the treatments. The unpruned treatments, which had no pruning except for the removal of branches that were in the way of shakers or tractors, had cumulative yields similar to the treatments that were pruned annually for the first 7 years.

Our results are in agreement with previous pruning studies in walnut that found no significant differences in yield with the exception of one season when unpruned yields were higher (Olson et al. 1990), but that trial was conducted on mature trees. In macadamia, yield decreased directly in proportion to severity of pruning (Olesen et al. 2011), with all pruning treatments resulting in significant retreatment. duction in yields except a light pruning

\section{References}

Adam M, Van Bussel LGJ, Leffelaar PA, et al. 2011. Effects of modeling detail on simulated potential crop yields under a wide range of climatic conditions. Ecol Model 222:131-43.

Aldrich T. 1972. A guide to minimum pruning. Diamond Walnut News 54:8-9.

Barritt BH, Rom CR, Konishi BJ, Dilley MA. 1991. Light level influences spur quality and canopy development and light interception influences fruit production in apple. HortScience 26:993-9.

California Soil Resource Lab. 2008. USDA-NCSS SSURGO and STATSGO Soil Survey Products. http://casoilresource. lawr.ucdavis.edu/drupal/node/902.

Fulton A, Buchner R, Olson B, et al. 2001. Rapid equilibration of leaf and stem water potential under field conditions in almonds, walnuts and prunes. HortTechnol ogy 11:609-15.

Grossman YL, DeJong TM. 1998. Training and pruning system effects on vegetative growth potential, light interception and cropping efficiency in peach trees. J Ame Soc Hort Sci 123:1058-64.
Decreases in nut size and quality have been documented in unpruned compared to pruned walnut (Olson et al. 1990) and pecan orchards (Worley 1991). However, in both cases the increase in return from improved nut quality was not sufficient to offset the labor costs of pruning. In our trial, there was no significant impact on either major sunburn or nut quality in any year (data not shown).

This study did not show any tree structure-, production- or nut quality-related advantages to pruning under the conditions of this trial. Since costs associated with pruning and disposal of prunings are high, as mentioned above, growers may be able to enhance economic returns by minimizing or eliminating pruning during the development phase of a Howard orchard. The results will not necessarily translate to all varieties and management systems, so caution should be used in implementing a no-pruning practice on a large scale. CA

B.D. Lampinen is UC Agriculture and Natural Resources Cooperative Extension (UCCE) Integrated Orchard Management Specialist in the Department of Plant Sciences at UC Davis; J.P. Edstrom is UCCE Farm Advisor Emeritus in Colusa County; S.G. Metcalf is Staff Research Associate, W.L. Stewart is Staff Research Associate, C.M. Negron was Graduate Student and M.L. Contador is Assistant Specialist in the Department of Plant Sciences at UCDavis.
Hasey JK, Kelley KM, Freeman MW. 1998. Training young trees. In: Ramos DE (ed.). Walnut Production Manual. UC ANR Pub 3373, Oakland, CA. p 99-105

Jackson JE. 1980. Light interception and utilization by orchard systems. Hort Rev 2:208-67.

Lampinen B, Udompetaikul V, Browne G, et al. 2012. A mobile platform for measuring canopy photosynthetically active radiation interception in orchard systems. HortTechnology 22:237-44.

McFadyen LM, Morris SG, Oldham MA, et al. 2004. The relationship between orchard crowding, light interception, and productivity in macadamia. Aust J Ag Res 55:1029-38

Olesen T, Huett D, Smith G. 2011. The production of flowers, fruit and leafy shoots in pruned macadamia trees. Funct Plant Biol 38:327-36.

Olson WH, Ramos DE, Ryugo K, Snyder RG. 1990. Annual and biennial pruning of mature lateral-bearing English walnuts. HortScience 25:756-8.

Rom CR. 1991. Light thresholds for apple tree canopy growth and development. HortScience 26:989-92.
Sabatier S, Barthélémy D. 2001. Bud structure in relation to shoot morphology and position on the vegetative annual shoots of Juglans regia L. (Juglandaceae). Ann Bot 87:117-23.

[UCCE] UC Cooperative Extension. 2012. Sample Costs to Establish a Walnut Orchard and Produce Walnuts - Sacramento Valley Microsprinkler Irrigated. http://coststudies.ucdavis.edu/current.php.

Worley RE. 1991. Selective limb pruning intensity influences mature pecan tree and nut characteristics. HortScience 26:126-9.

Wunsche JN, Lakso AN. 2000. The relationship between leaf area and light interception by spur and extension shoot leaves and apple orchard productivity. HortScience 35:1202-6.

Wunsche JN, Lakso AN, Robinson TL, et al. 1996. The bases of productivity in apple production systems: The role of light interception by different shoot types. J Amer Soc Hort Sci 121:886-93. 